\title{
Microwave Spectrum, Structure and Rotation-Vibration Interaction of Deutero-Fulminic Acid, DCNO*
}

\author{
HANS Karl Bodenseh \\ Lehrstuhl für Physikalische Chemie, Universität Ulm \\ and MANFRED WINNEWISSER \\ Institut für Physikalische Chemie, Universität Kiel \\ (Z. Naturforsch. 24 a, 1973-1979 [1969]; received 2 August 1969)
}

\begin{abstract}
The microwave spectrum of the deuterated form of fulminic acid (DCNO) has been investigated in the frequency region from 9 to $42 \mathrm{GHz}$. For the ground vibrational state of DCNO the following rotational constants were obtained:

$$
\begin{aligned}
& B_{0}\left(\mathrm{D}^{12} \mathrm{C}^{14} \mathrm{~N}^{16} \mathrm{O}\right)=10292.50 \mathrm{MHz}, \\
& B_{0}\left(\mathrm{D}^{13} \mathrm{C}^{14} \mathrm{~N}^{16} \mathrm{O}\right)=10011.66 \mathrm{MHz}, \\
& B_{0}\left(\mathrm{D}^{12} \mathrm{C}^{14} \mathrm{~N}^{18} \mathrm{O}\right)=9758.87 \mathrm{MHz} .
\end{aligned}
$$

The corresponding moments of inertia yield a combined $r_{\mathrm{s}}$ and $r_{0}$ structure :$$
r_{\mathrm{DC}}=1.027 \pm 0.001 \AA, \quad r_{\mathrm{CN}}=1.168 \pm 0.001 \AA, \quad r_{\mathrm{NO}}=1.199 \pm 0.001 \AA .
$$

For the two degenerate bending modes $v_{4}$ and $v_{5}$ the $l$-type doublets of the transition $J=1-2$ and the two corresponding series of $l$-type doubling transitions have been observed. The analysis of the two $l$-type doubling series revealed that $P^{4}$ and $P^{6}$ centrifugal distortion contributions are sufficient to account for the spectrum. The doubling constants given in $\mathrm{MHz}$ are

$$
\begin{aligned}
& q_{4}=17.9103-\left(0.6467 \cdot 10^{-4}\right) J(J+1)+\left(0.188 \cdot 10^{-8}\right)[J(J+1)]^{2}, \\
& q_{5}=38.0907-\left(0.3061 \cdot 10^{-3}\right) J(J+1)+\left(0.314 \cdot 10^{-8}\right)[J(J+1)]^{2} .
\end{aligned}
$$

A third series of $l$-type doubling transitions arising from the $\Pi$-level of the $\nu_{5}=3$ vibrational state has been found and analysed, yielding:

$$
q_{3 \times 5}^{(0)}=29.2748 \pm 1.8 \cdot 10^{-4} \mathrm{MHz} ; \quad E_{\Phi}-E_{\Pi}=\Delta \cong 41 \mathrm{~cm}^{-1} .
$$
\end{abstract}

Recently the microwave rotational spectra of fulminic acid (HCNO) and several of its isotopic species have been reported ${ }^{1,2}$. The molecule was found to have a linear arrangement of the atoms $\mathrm{H}-\mathrm{C}-\mathrm{N}-\mathrm{O}$. The present investigation of the microwave spectra of the deuterated form of fulminic acid and of its ${ }^{13} \mathrm{C}$ and ${ }^{18} \mathrm{O}$ labeled species in natural aboundance was made possible by the large dipole moment of 3.06 Debye found for $\mathrm{HCNO}^{1}$. Therefore it was possible to consider DCNO as parent molecule for the determination of an independent $r_{\mathrm{s}}$ and $r_{0}$-structure calculation, thus leading to an improved structure of fulminic acid.

The substitution of $\mathrm{H}$ by $\mathrm{D}$ in such a small molecule alters the vibrational energy level scheme considerably, which in return should manifest itself in a change in the rotation-vibration interaction observed in the microwave spectrum of such a mole-

Reprint requests to Dr. M. WinNewisser, Institut für Physikalische Chemie der Universität Kiel, D-2300 Kiel, Olshausenstraße.

* Presented in part at the Chemiedozententagung 1968, April $3-5$ in Hamburg, and at the 23rd Symposium on Molecular Structure and Spectroscopy at the Ohio State University, Columbus, Ohio, September 3-7, 1968. cule. The two anomalies observed in DCNO with respect to the value of $q_{3 \times 5}^{(0)}$ and the rotational constant for the vibrational state $0000^{0} 2^{0}$ are of the same type and magnitude as in the case of the HCNO molecule ${ }^{2}$.

\section{Experimental}

Deutero-fulminic acid was prepared in analogy to the synthesis of HCNO as described in ${ }^{1}$. After synthesis of $\mathrm{Hg}$-fulminate the solid fulminate is washed and dried under vacuum at $+30{ }^{\circ} \mathrm{C}$ to $+35{ }^{\circ} \mathrm{C}$. Some caution should be exercised since at $100^{\circ} \mathrm{C}$ Hg-fulminate will explode spontaneously even before it dries out. $\mathrm{D}_{2} \mathrm{O}$ is then carefully added to the dried powder forming a suspension which is reduced by the addition of sodium-amalgam. Gaseous deutero-fulminic acid may then be obtained by the reaction of deutero-sulfuric acid with the heavy water solution of sodium fulminate. A strong stream of nitrogen is used as carrier gas to

1 M. Winnewisser and H. K. Bodenseh, Z. Naturforsch. 22 a, 1724 [1967].

2 H. K. Bodenseh and M. Winnewisser, Z. Naturforsch. 24 a, 1966 [1969]. 
remove the gaseous DCNO from the reacting solution. DCN is formed as a side product in this reaction, while DNCO occurs as a rather stable end product of the decomposition of DCNO.

It was observed that the exchange of the hydrogen atom of the compound proceeds very rapidly. Under the conditions prevailing in the absorption cell (room temperature, $10^{-3}$ Torr pressure) the rate of exchange was faster than the rate of decomposition by several orders of magnitude. To maintain a useful concentration of DCNO in the cell it was necessary to fill all vessels which might contain the substance, including the absorption cell, with about 1 Torr of $\mathrm{D}_{2} \mathrm{O}$ and pump it out, repeatedly. With these precautions, a concentration of $50 \%$ DCNO $-50 \%$ HCNO could be maintained in the cell.

The $100 \mathrm{kHz}$ Stark spectrograph used for the measurements has been described in Ref. ${ }^{1}$.

\section{Measurements}

The microwave spectrum of the compound in the frequency range $9-42 \mathrm{GHz}$ was measured. In this region are found the $J=0 \rightarrow 1$ and $J=1 \rightarrow 2$ transitions of the rotational R-branch for several isotopic combinations and of molecules in several excited vibrational states. The observed transitions of this type and the molecular constants derived from them are listed in Table 1. Three $Q$-branches, or l-type doubling transition series for states with $l=1$, were observed. The series for $v_{4}=1$ is listed in Table 7, the series for $v_{5}=1$ is listed in Table 8 and the series assigned to $v_{5}=3$ is listed in Table 10. A Fortrat diagram representing all of these transitions is shown in Fig. 1.



Fig. 1. Fortrat diagram of the microwave transitions of $\mathrm{D}^{12} \mathrm{C}^{14} \mathrm{~N}^{16} \mathrm{O}$.

\section{Molecules in the Ground State and Structure}

First it must be mentioned that the rotational constant of the $\mathrm{D}^{12} \mathrm{C}^{14} \mathrm{~N}^{16} \mathrm{O}$ molecule does not agree within the error limits for the $J=0 \rightarrow 1$ and $J=$ $1 \rightarrow 2$ transitions. Since no noticeable effect due to centrifugal distortion could be observed for these transitions in HCNO, this cannot be the explanation

\begin{tabular}{|c|c|c|c|c|c|c|c|}
\hline \multirow[t]{2}{*}{ Molecule } & \multirow[t]{2}{*}{$\begin{array}{c}\text { Rotational } \\
\text { transition }\end{array}$} & \multirow{2}{*}{$\begin{array}{c}\text { Vibrational } \\
\text { state } \\
v_{1} v_{2} v_{3} v_{4}^{l} v_{5}^{l}\end{array}$} & \multirow[t]{2}{*}{$\begin{array}{l}\text { Symmetrie } \\
\text { species }\end{array}$} & \multirow{2}{*}{$\begin{array}{c}\text { Measured } \\
\text { frequencies } \\
f(\mathrm{MHz})\end{array}$} & \multicolumn{2}{|c|}{$\begin{array}{l}\text { Spectroscopic } \\
\text { constants }\end{array}$} & \multirow{2}{*}{$\begin{array}{l}\text { Moments } \\
\text { of inertia } \\
\left(\mathrm{amu} \cdot \AA^{2}\right)\end{array}$} \\
\hline & & & & & $B_{v}(\mathrm{MHz})$ & $\alpha_{v}(\mathrm{MHz})$ & \\
\hline \multirow[t]{13}{*}{$\mathrm{D}^{12} \mathrm{C}^{14} \mathrm{~N}^{16} \mathrm{O}$} & $J=0 \rightarrow 1$ & $\begin{array}{lllll}0 & 0 & 0 & 0^{0} & 0^{0}\end{array}$ & $\Sigma^{+}$ & $20585.00 \pm 0.05$ & 10292.50 & & 49.11644 \\
\hline & & $\begin{array}{lllll}0 & 0 & 1 & 0^{0} & 0^{0}\end{array}$ & $\Sigma^{+}$ & $20499.8 \pm 0.5$ & 10249.9 & +42.6 & \\
\hline & & $\begin{array}{lllll}0 & 0 & 0 & 2^{0} & 0^{0}\end{array}$ & $\Sigma^{+}$ & $20636.35 \pm 0.1$ & 10318.18 & -25.68 & \\
\hline & & $\begin{array}{lllll}0 & 0 & 0 & 0^{0} & 2^{0}\end{array}$ & $\Sigma^{+}$ & $20724.45 \pm 0.05$ & 10362.23 & -69.73 & \\
\hline & & $\begin{array}{llll}0 & 0 & 0 & \left(\begin{array}{ll}1 & 1\end{array}\right)^{0}\end{array}$ & $\Sigma^{+} \mathrm{b}_{\mathrm{b}}$ & $20702.26 \pm 0.05$ & 10351.13 & -58.63 & \\
\hline & & 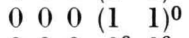 & $\left.\Sigma^{-}\right\}^{0}$ & $20703.94 \pm 0.05$ & 10351.97 & -59.47 & \\
\hline & $J=1 \rightarrow 2$ & $\begin{array}{lllll}0 & 0 & 0 & 0^{0} & 0^{0}\end{array}$ & $\Sigma+$ & $41169.84 \pm 0.05$ & 10292.46 & & \\
\hline & & $\begin{array}{lllll}0 & 0 & 0 & 1_{1}^{1} & 0^{0} \\
0 & 0 & 0 & l_{1} & 0^{0}\end{array}$ & $\Pi$ & $41188.09 \pm 0.1$ & 10305.99 & -13.53 & \\
\hline & & $\begin{array}{lllll}0 & 0 & 0 & 1_{2}^{1} & 0^{0} \\
0 & 0 & 0 & 0^{0} & 1_{1}^{1}\end{array}$ & $\begin{array}{l}\Pi 1 \\
\Pi I\end{array}$ & $\begin{array}{l}41259.83 \pm 0.1 \\
41278.60+0.1\end{array}$ & & & \\
\hline & & $\begin{array}{lllll}0 & 0 & 0 & 0^{0} & 1_{2}^{1}\end{array}$ & $\Pi$ & $41430.84 \pm 0.1$ & 10338.68 & -46.22 & \\
\hline & & $\begin{array}{lllll}0 & 0 & 0 & 0^{0} & 2^{0}\end{array}$ & $\Sigma^{+}$ & $41449.4 \pm 0.5$ & 10362.3 & -69.8 & \\
\hline & & 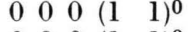 & $\Sigma^{+} l_{b}$ & $41404.45 \pm 0.1$ & 10351.11 & -58.65 & \\
\hline & . & 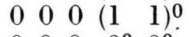 & $\left.\Sigma^{-}\right\}$ & $41407.7 \pm 0.5$ & 10351.9 & -59.4 & \\
\hline $\mathrm{D}^{13} \mathrm{C}^{14} \mathrm{~N}^{16} \mathrm{O}$ & $J=0 \rightarrow 1$ & $\begin{array}{lllll}0 & 0 & 0 & 0^{0} & 0^{0}\end{array}$ & $\Sigma^{+}$ & $20023.32 \pm 0.05$ & 10011.66 & & 50.49422 \\
\hline $\mathrm{D}^{12} \mathrm{C}^{14} \mathrm{~N}^{18} \mathrm{O}$ & $J=0 \rightarrow 1$ & $\begin{array}{lllll}0 & 0 & 0 & 0^{0} & 0^{0}\end{array}$ & $\Sigma^{+}$ & $19519.74 \pm 0.05$ & 9759.87 & & 51.79690 \\
\hline
\end{tabular}

${ }^{a}$ Conversion factor: $B \times I=505531 \mathrm{MHz} \cdot \mathrm{amu} \cdot \AA^{2}$; atomic weight: ${ }^{16} \mathrm{O}=16.000000$.

b The given symmetry designation + or - of these two $\Sigma$-states is arbitrary since the microwave measurements do not allow this to be determined.

Table 1. Measured line frequencies and spectroscopic constants for the assigned vibrational states of three isotopic species of DCNO. 
here. The discrepancy is most likely to be caused by the complex hyperfine structure of the DCNO transitions, since not only the nitrogen $\left({ }^{14} \mathrm{~N}\right)$ but also the deuterium has spin 1 . The quadrupole hyperfine splitting is not so large that the components can be resolved, but the measured intensity maximum may not be equally far from the line center $f_{0}$ in the different transitions observed.

The structure of DCNO may be calculated from the moments of inertia given in Table 1 in just the same way it was done for $\mathrm{HCNO}^{1}$. Together with the value of $I_{0}\left(\mathrm{H}^{12} \mathrm{C}^{14} \mathrm{~N}^{16} \mathrm{O}\right)$ from Ref. ${ }^{1}$, these values can be used to calculate the substitution coordinates of the $\mathrm{D}, \mathrm{C}$, and $\mathrm{O}$ atoms, as presented in Table 2.

\begin{tabular}{|c|c|c|c|}
\hline $\begin{array}{c}i \text {-th } \\
\text { atom }\end{array}$ & $\begin{array}{c}m_{i} \\
\mathrm{amu}\end{array}$ & $\begin{array}{l}z_{i} \\
\AA\end{array}$ & $\begin{array}{c}m_{i} z_{i} \\
\mathrm{amu} \cdot \AA\end{array}$ \\
\hline D & 2.014735 & 2.2116 & 4.4557 \\
\hline C & 12.003804 & 1.1849 & 14.2238 \\
\hline 0 & 16.000000 & 1.1823 & 18.9171 \\
\hline $\mathbf{N}$ & 14.007515 & $\left.0,0547^{a}\right)$ & 0.7666 \\
\hline
\end{tabular}

a From Eq. (1).

Table 2. Substitution coordinates $z_{i}$ and products of inertia $m_{i} z_{i}$ of $\mathrm{D}^{12} \mathrm{C}^{14} \mathrm{~N}^{16} \mathrm{O}$.

The replacement of the hydrogen by deuterium in fulminic acid moves the center of mass even closer to the central nitrogen atom, from about $0.07 \AA$ in HCNO (Ref. ${ }^{1}$ ) to about $0.02 \AA$ in DCNO. Therefore, the $\mathrm{N}$-coordinate as obtained from the equation for the moment of inertia

$$
I_{0}\left(\mathrm{D}^{12} \mathrm{C}^{14} \mathrm{~N}^{16} \mathrm{O}\right)=\sum_{i} m_{i} z_{i}^{2}
$$

and also entered in Table 2 is even less physically meaningful than in the case of HCNO. This is confirmed by looking at how exactly the center of mass condition is fulfilled using the coordinates given in Table 2. Using the appropriate signs, one obtains

$$
\sum_{i} m_{i} z_{i}=0.5290 \mathrm{amu} \cdot \AA \text {. }
$$

If the center of mass condition is used to determine the nitrogen atom coordinate, we have

$$
\sum_{i} m_{i} z_{i}=0, \quad z_{\mathrm{N}}=-0.0170 \AA .
$$

The difference between the values arrived at by these two methods is $0.0377 \AA$, as opposed to $0.0151 \AA$ for HCNO. The interatomic distances determined from these coordinates for DCNO and HCNO are compared in Table 3 . The following points should be noted:

1) The distances $r_{\mathrm{s}}$, determined strictly from substitution coordinates for $\mathrm{D}, \mathrm{H}, \mathrm{C}$ and $\mathrm{O}$, agree to within a few tenthousandths of an Ångstrom unit for the two molecules.

2) The distances $r(\mathrm{C}-\mathrm{N})$ and $r(\mathrm{~N}-\mathrm{O})$ agree within the same accuracy if the $\mathrm{N}$ atom coordinates are used which were obtained by the center of mass condition. If, on the other hand, the coordinates are used which were obtained by Eq. (1), the values of these interatomic distances differ markedly in the two molecules.

3) Interatomic distances involving oxygen remain the same whether ${ }^{17} \mathrm{O}$ or ${ }^{18} \mathrm{O}$ was used to obtain the substitution coordinate.

Thus the measurements of the fulminic acid provide further evidence for the reliability of the substitution method for structure determination developed by Kraitchman ${ }^{3}$ and Costain ${ }^{4}$. Fulminic acid is a relatively light molecule, so that the frequencies of the same transition for different isotopic species lie several hundred or even thousand $\mathrm{MHz}$ apart. Since the moments of inertia have the same accuracy, in percent, as the transition frequencies, many significant figures remain when differences are taken, and the experimental accuracy of the substitution coordinates is very good. The

\begin{tabular}{|c|c|c|c|c|c|c|c|}
\hline & \multirow[t]{2}{*}{$r_{\mathrm{H}(\mathrm{D})-\mathrm{C}}$} & \multirow[t]{2}{*}{$r_{\mathrm{C}-0}$} & $r_{\mathrm{C}-\mathrm{N}}$ & $r_{\mathrm{N}-0}$ & $\begin{aligned} r_{\mathrm{C}-\mathrm{N}} \\
\text { ted by }\end{aligned}$ & $r_{\mathrm{N}-0}$ & \multirow[t]{2}{*}{$\Delta z_{\mathrm{N}^{\mathrm{a}}}^{\mathrm{a}}$} \\
\hline & & & \multicolumn{4}{|c|}{$\begin{array}{c}\text { N-coordinate calculated by using } \\
\sum_{i} m_{i} z_{i}=0 \\
I_{0}=\sum_{i} m_{i} z^{2}\end{array}$} & \\
\hline HCNO- ${ }^{17} \mathrm{O}$ & & 2.3671 & & 1.1992 & & 1.2144 & \\
\hline HCNO- ${ }^{18} \mathrm{O}$ & 1.0266 & 2.3674 & 1.1679 & 1.1995 & 1.1528 & 1.2147 & 0.0151 \\
\hline DCNO-18O & 1.0266 & 2.3672 & 1.1679 & 1.1993 & 1.1302 & 1.2370 & 0.0377 \\
\hline
\end{tabular}
small discrepancies between the two molecules are, however, still due to experimental error: The fre-

a $\Delta z_{\mathrm{N}}=$ difference in the $\mathrm{N}$-coordinates calculated by using $\Sigma m_{i} z_{i}=0$ and Eq. (1).

Table 3. Internuclear distances of HCNO and DCNO. All entries are in Å-units.
3 J. Kraitchman, Am. J. Phys. 21, 17 [1953].
${ }^{4}$ C. C. Costain, J. Chem. Phys. 29, 864 [1958]. 
quencies at about $20 \mathrm{GHz}$ are accurate to $1: 400000$. This accuracy is limited by the decomposition of the compound. The moments of inertia are about $50 \mathrm{amu} \cdot \AA^{2}$, so that they are accurate to within \pm 1 in the sixth significant figure. In taking differences of the moments of inertia only the first digit is lost, so that five significant figures remain, with the last one uncertain within two units. Since one interatomic distance requires two such coordinates, it will be accurate to within \pm 4 in the last digit, which corresponds closely to the observed deviations of $3 / 10000 \AA$. It is remarkable that the results are this accurate even when the center of mass condition is used. This relation appears to be the best method of determining a coordinate which is inaccessible through substitution, either because of lack of an appropriate isotope or because of the location of the center of mass very close to the atom in question.

By averaging the values for the two molecules given in Table 3 the values for the interatomic distances in fulminic acid were arrived at which are given in Fig. 2. The actual error should be considerably less than the given uncertainty of $\pm 0.001 \AA$.



Fig. 2. Improved structure of fulminic acid. Accuracy in the internuclear distances: $\pm 0.001 \AA$.

\section{Molecules in Excited Vibrational States}

\section{a) Vibrational satellites of the R-branch transitions of $D^{12} C^{14} N^{16} O$}

The fundamental vibration frequencies of DCNO are not yet known. However, we can estimate the frequencies of the fundamentals relevant for this investigation, $v_{3}, v_{4}$ and $v_{5}$. The hydrogen atom participates only weakly in the motions associated with $v_{3}$ and $v_{5}$, so that we may expect them to fall about $10 \%$ lower in frequency than in HCNO. The DCN bending mode $v_{4}$ in DCNO, on the other hand, could be as low as $400 \mathrm{~cm}^{-1}$ or even less, compared to $538 \mathrm{~cm}^{-1}$ in HCNO. Thus it can be estimated that $v_{4}$ and $v_{5}$ will be separated by only about $100 \mathrm{~cm}^{-1}$. The fundamental frequencies of HCNO are given in Ref. ${ }^{1}$.
The assignment of the observed transitions is based on the same considerations as in the case of $\mathrm{HCNO}^{2}$. As in that molecule, the values of $\alpha_{v}$ for the vibrational states $0001^{1} 0^{0}$ and $0000^{0} 1^{1}$ may be used to estimate the rotational constants for higher excited states and combination states according to the relation

$$
B_{v}=B_{\mathrm{e}}-\sum_{i} \alpha_{i}\left(v_{i}+d_{i} / 2\right) .
$$

When the rotational constants corresponding to the observed transitions are plotted and compared to those observed for HCNO, as is done in Fig. 3,

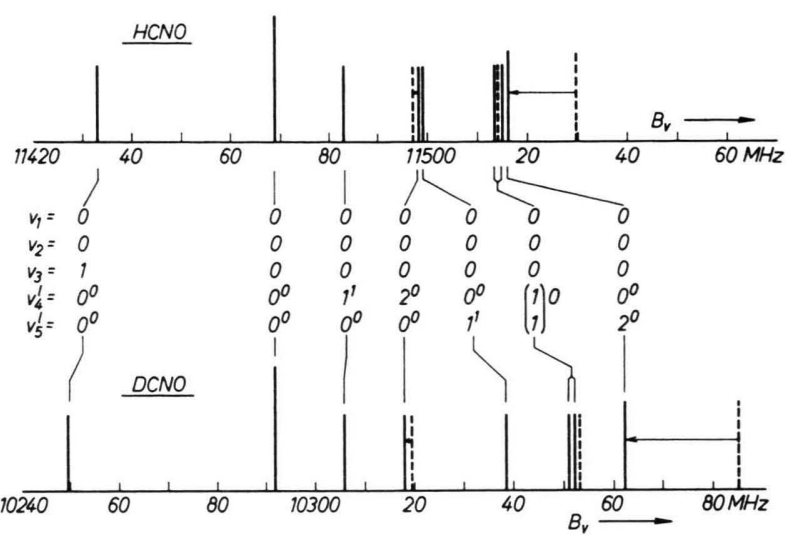

Fig. 3. Measured (solid lines) and calculated (dotted lines) rotational constants of different vibrational states of the molecules $\mathrm{H}^{12} \mathrm{C}^{14} \mathrm{~N}^{16} \mathrm{O}$ and $\mathrm{D}^{12} \mathrm{C}^{14} \mathrm{~N}^{16} \mathrm{O}$.

the assignment of the DCNO transitions may be determined by inspection. There are only two significant differences:

1) The $\left|\alpha_{v}\right|$ for $0000^{0} 1^{1}$ is considerably larger for DCNO than for HCNO.

2) Because of this difference, the rotational constant for $0000^{0} 2^{0}$ does not lie close to those for the two states $000(11)^{0}$.

The following properties of the DCNO spectrum are analogous to those of the HCNO spectrum:

1) The $\alpha_{v}$ for $0002^{0} 0^{0}$ is nearly exactly twice that for $0001^{1} 0^{0}$.

2) The state $000(11)^{0}$ exhibits two slightly different rotational constants corresponding to the nearly degenerate $\Sigma^{+}$and $\Sigma^{-}$levels.

3) The $\alpha_{v}$ for $000(11)^{0}$ is very nearly equal to the sum of the $\alpha_{v}$ 's for $0001^{1} 0^{0}$ and $0000^{0} 1^{1}$.

4) The rotational constant for $0000^{0} 2^{0}$ deviates considerably from the value predicted by Eq. (2). 
The exact values illustrating these points are

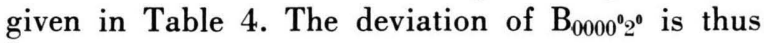
seen to be characteristic of the fulminic acid.

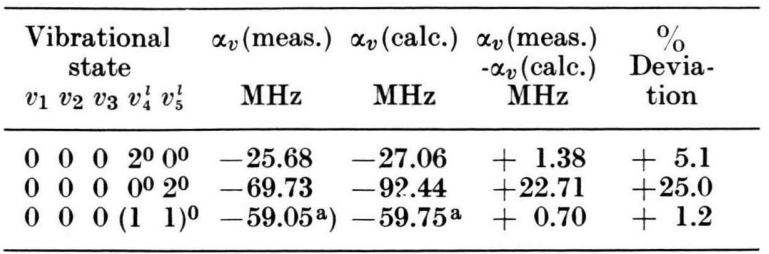

a Average values of the two components of the $\left(\Sigma^{-}, \Sigma^{+}\right)$ doublet.

Table 4. Calculated and measured values of the vibration-rotation-interaction constant $\alpha_{v}$ for the $v_{4}$ and $v_{5}$ vibrational satellites of $\mathrm{D}^{12} \mathrm{C}^{14} \mathrm{~N}^{16} \mathrm{O}$.

\section{b) Analysis of the observed l-type doubling transi- tions for the $0001^{1} 0^{0}$ and $0000^{0} 1^{1}$ vibrational states of $D^{12} \mathrm{C}^{14} \mathrm{~N}^{16} \mathrm{O}$}

As may be seen in Table 1 , the constants $q_{4}{ }^{(0)}$ and $q_{5}{ }^{(0)}$ were determined from the $l$-type doublets of the rotational transition $J=1 \rightarrow 2$. The values of these two constants are given in Table 5. Although $q_{5}{ }^{(0)}$ changes only by about $10 \%$ in going from HCNO to DCNO, the value of $q_{4}{ }^{(0)}$ changes by $24 \%$.

Direct $l$-type transitions $\quad$ Rotational $l$-type doublets

$q_{4}^{(0)}=17.9103 \pm 0.0002 \mathrm{MHz} \quad q_{4}^{(0)}=17.93 \pm 0.05 \mathrm{MHz}$ $q_{5}^{(0)}=38.0907 \pm 0.0001 \mathrm{MHz} \quad q_{5}^{(0)}=38.06 \pm 0.05 \mathrm{MHz}$

Table 5. Comparison between the $l$-type doubling constants obtained by analysis of the direct $l$-type transitions and by using the $l$-type doublets of the rotational transition $J=1 \rightarrow 2$ of $v_{4}=1$ and $v_{5}=1$ of $\mathrm{D}^{12} \mathrm{C}^{14} \mathrm{~N}^{16} \mathrm{O}$.
This confirms the assignment of the $l$-type doublets, which was based first of all on relative intensity, since the vibrational mode $v_{4}$ involves mainly the HCN (DCN) bending motion.

The corresponding series of direct $l$-type doubling transitions were also observed for both bending modes. The analysis in Table 6 shows that the inclusion of $P^{6}$-terms was sufficient to reproduce the observed frequencies within the experimental error for both series. Thus the calculated frequencies in Tables 7 and 8 are evaluated from the expression $f=q_{t}^{(0)} J(J+1)-q_{\mathrm{t}}^{(1)}[J(J+1)]^{2}$

$$
+q_{\mathrm{t}}^{(2)}[J(J+1)]^{3} \text {. }
$$

In going from HCNO to DCNO a distinct decrease in the effect of centrifugal distortion in the state $v_{4}=1$ may be observed. For $v_{5}=1$ there is no significant change in the constants obtained. This again is consistent with the assignment of $\boldsymbol{v}_{4}$ to the HCN bending mode. However, there is no parallel for this result in the data for HCN and DCN. In DCN the constants $q^{(1)}$ and $q^{(2)}$ change only by an amount corresponding to the change in $q^{(0) 5}$. In the case of deutero-fulminic acid the extreme $\left(P^{8}\right)$ centrifugal distortion effects observed for $v_{4}$ in HCNO are not present. Even the $P^{4}$ and $P^{6}$ effects for $v_{4}$ in DCNO are smaller than for $v_{5}$. This may be seen from Tables 7 and 8. A comparison of the values for $q_{\mathrm{t}}^{(0)}$ obtained from the series and from the rotational $l$-type doublets of the $J=1 \rightarrow 2$ transition is given in Table 5 . The least squares analysis and the significance of the given error limits are discussed in Ref. ${ }^{1}$.

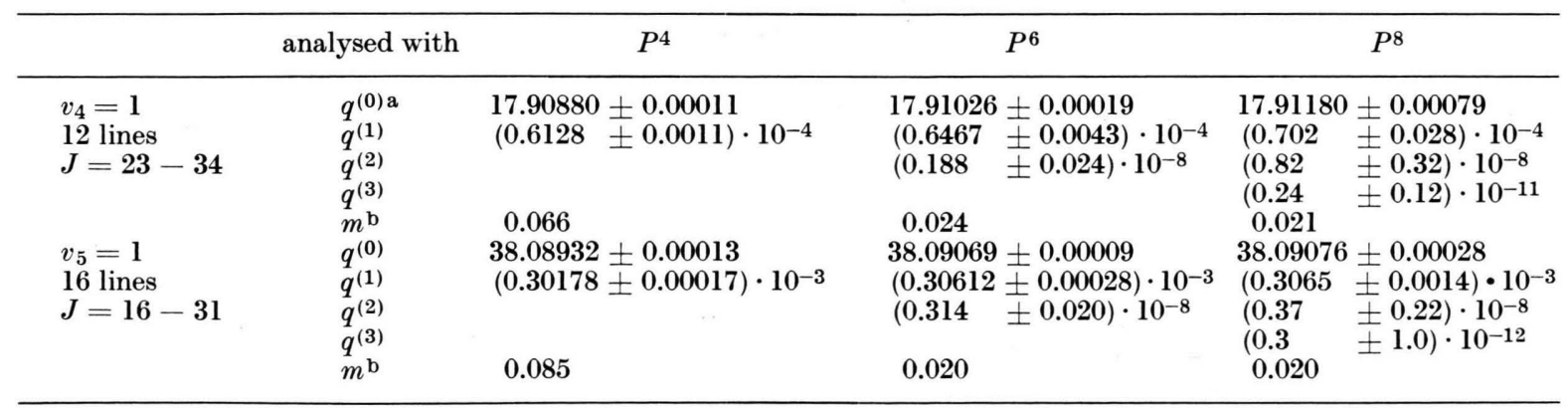

\footnotetext{
a All constants in MHz. - ${ }^{\mathrm{b}}$ Standard deviation of the fit.
}

Table 6. Results of the centrifugal distortion analysis of the direct $l$-type doubling transitions for $\mathrm{D}^{12} \mathrm{C}^{14} \mathrm{~N}^{16} \mathrm{O}$ molecules in the $v_{4}=1$ and $v_{5}=1$ vibrational state.

5 A. G. Maki, Jr., and D. R. Lide, JR., J. Chem. Phys. 47, 3206 [1967]. 


\begin{tabular}{|c|c|c|c|c|c|c|}
\hline$J$ & $\begin{array}{c}q_{4}^{(0)} J(J+1) \\
\mathrm{MHz}\end{array}$ & $\begin{array}{c}-q_{4}^{(1)}[J(J+1)]^{2} \\
\mathrm{MHz}\end{array}$ & $\begin{array}{c}q_{4}^{(2)}[J(J+1)]^{3} \\
\mathrm{MHz}\end{array}$ & $\begin{array}{l}\text { Calculated } \\
\text { frequencies } \\
\mathrm{MHz}\end{array}$ & $\begin{array}{c}\text { Measured } \\
\text { frequencies }^{\mathrm{a}} \\
\text { MHz }\end{array}$ & $\begin{array}{c}f \text { (meas.) }-f \text { (calc. }) \\
\mathrm{MHz}\end{array}$ \\
\hline 23 & 9886.46 & -19.71 & 0.32 & 9876.07 & 9867.07 & 0.00 \\
\hline 24 & 10746.16 & -23.28 & 0.41 & 10723.28 & 10723.31 & +0.03 \\
\hline 25 & 11641.67 & -27.32 & 0.52 & 11614.86 & 11614.87 & +0.01 \\
\hline 26 & 12573.00 & -31.87 & 0.65 & 12541.78 & 12541.78 & 0.00 \\
\hline 27 & 13540.16 & -36.96 & 0.81 & 13504.01 & 13503.98 & -0.03 \\
\hline 28 & 14543.13 & -42.64 & 1.01 & 14501.50 & 14501.49 & -0.01 \\
\hline 29 & 15581.93 & -48.95 & 1.24 & 15534.21 & 15534.21 & 0.00 \\
\hline 30 & 16656.54 & -55.93 & 1.51 & 16602.12 & 16602.10 & -0.02 \\
\hline 31 & 17766.98 & -63.64 & 1.83 & 17705.17 & 17705.17 & 0.00 \\
\hline 32 & 18913.24 & -72.12 & 2.21 & 18843.33 & 18843.38 & +0.05 \\
\hline 33 & 20095.31 & -81.41 & 2.65 & 20016.55 & 20016.56 & +0.01 \\
\hline 34 & 21313.21 & -91.58 & 3.16 & 21224.79 & 21224.77 & -0.02 \\
\hline
\end{tabular}

a The experimental uncertainties of the measured frequencies are believed to be of the order $\pm 0.05 \mathrm{MHz}$.

Table 7. Direct $l$-type doublet transitions for the $0001^{1} 0^{0}$ vibrational state of $\mathrm{D}^{12} \mathrm{C}^{14} \mathrm{~N}^{16} \mathrm{O}$. The calculated frequencies were obtained by using a polynominal fit to account for centrifugal distortion. The constants used in the calculations are given in Table 6, column " $P$ " ".

\begin{tabular}{|c|c|c|c|c|c|c|}
\hline$J$ & $\begin{array}{c}q_{5}^{(0)} J(J+1) \\
\mathrm{MHz}\end{array}$ & $\begin{array}{c}-q_{5}^{(1)}[J(J+1)]^{2} \\
\mathrm{MHz}\end{array}$ & $\begin{array}{c}q_{\mathrm{s}}^{(2)}[J(J+1)]^{3} \\
\mathrm{MHz}\end{array}$ & $\begin{array}{c}\text { Calculated } \\
\text { frequencies } \\
\text { MHz }\end{array}$ & $\begin{array}{c}\text { Measured } \\
\text { frequencies } \\
\text { MHz }\end{array}$ & $\begin{array}{c}f \text { (meas.) }-f \text { (calc. }) \\
\mathrm{MHz}\end{array}$ \\
\hline 16 & 10360.67 & -22.65 & 0.06 & 10338.08 & 10338.07 & -0.01 \\
\hline 17 & 11655.75 & -28.66 & 0.09 & 11627.18 & 11627.19 & +0.01 \\
\hline 18 & 13027.02 & -35.81 & 0.13 & 12991.34 & 12991.35 & +0.01 \\
\hline 19 & 14474.46 & -44.20 & 0.17 & 14430.43 & 14430.43 & 0.00 \\
\hline 20 & 15998.09 & -54.00 & 0.23 & 15944.32 & 15944.31 & -0.01 \\
\hline 21 & 17597.90 & -65.34 & 0.31 & 17532.87 & 17532.86 & -0.01 \\
\hline 22 & 19273.89 & -78.38 & 0.41 & 19195.92 & 19195.93 & +0.01 \\
\hline 23 & 21026.06 & -93.28 & 0.53 & 20933.31 & 20933.31 & 0.00 \\
\hline 24 & 22854.41 & -110.20 & 0.68 & 22744.89 & 22744.87 & -0.02 \\
\hline 25 & 24758.95 & -129.34 & 0.86 & 24630.47 & 24630.46 & -0.01 \\
\hline 26 & 26739.66 & -150.86 & 1.09 & 26589.89 & 26589.91 & +0.02 \\
\hline 27 & 28796.56 & -174.96 & 1.36 & 28622.96 & 28622.98 & +0.02 \\
\hline 28 & 30929.64 & -201.84 & 1.68 & 30729.48 & 30729.49 & +0.01 \\
\hline 29 & 33138.90 & -231.70 & 2.07 & 32909.26 & 32909.22 & -0.04 \\
\hline 30 & 35424.34 & -264.76 & 2.53 & 35162.10 & 35162.13 & +0.03 \\
\hline 31 & 37785.96 & -301.24 & 3.07 & 37487.79 & 37487.78 & -0.01 \\
\hline
\end{tabular}

a The experimental uncertaintines of the measured frequencies are believed to be of the order $\pm 0.05 \mathrm{MHz}$.

Table 8. Direct $l$-type doublet transitions for the $0000^{0} 1^{1}$ vibrational state of $\mathrm{D}^{12} \mathrm{C}^{14} \mathrm{~N}^{16} \mathrm{O}$. The calculated frequencies were obtained by using a polynominal fit to account for centrifugal distortion. The constants used in the calculations are given in Table 6, column " $P^{6}$ ".

c) Analysis of the observed l-type doubling transitions for the $0000^{0} 3^{1}$ vibrational state of

$$
D^{12} C^{14} N^{16} \mathrm{O}
$$

A further parallel to the measurements on HCNO is the observation and measurement of the direct l-type doubling transitions for the vibrational state $v_{5}=3$ in DCNO. As discussed in Ref. ${ }^{2}$, these frequencies can be analysed by considering simultaneously the $l$-type doubling of the $l=1$ levels and $l$-type resonance with the $l=3$ levels. As in the analogous calculation for HCNO, the constant $q_{3 \times 5}^{(2)}$ could not be determined from the data. Therefore the analysis was carried out both

1) with $q_{3 \times 5}^{(2)}=0$, and

2) with the assumption that $q_{3 \times 5}^{(2)}=q_{1 \times 5}^{(2)}=$ $3.14 \cdot 10^{-9} \mathrm{MHz}$.

The results of both procedures are presented in Table 9. The calculated line frequencies in Table 10 were obtained using the constants of method II.

The results of this analysis are analogous to those for HCNO in that

1) $q_{5}^{(0)}$ decreases from $38.09 \mathrm{MHz}$ for $v_{5}=1$ to $29.27 \mathrm{MHz}$ for $v_{5}=3$, and 


\begin{tabular}{|c|c|c|c|c|}
\hline & $\begin{array}{l}q_{3 \times 5}^{(0)} \\
\mathrm{MHz}\end{array}$ & $\begin{array}{l}q_{3 \times 5}^{(1)} \\
\mathrm{MHz}\end{array}$ & $\begin{array}{l}\Delta_{0} \\
\mathrm{MHz}\end{array}$ & $\begin{array}{c}\text { Standard } \\
\text { deviation } \\
\text { of fit } \\
\mathrm{MHz}\end{array}$ \\
\hline $\begin{array}{l}\text { Method I } \\
q_{3 \times 5}^{(2)}=0\end{array}$ & $29.27475 \pm 1.7 \cdot 10^{-4}$ & $(1.4130 \pm 0.0082) \cdot 10^{-4}$ & $(1.414 \pm 0.073) \cdot 10^{6}$ & 0.037 \\
\hline $\begin{array}{l}\text { Method II } \\
q_{3 \times 5}^{(2)}=q_{1 \times 5}^{(2)}=3.1 \cdot 10^{-9}\end{array}$ & $29.27478 \pm 1.8 \cdot 10^{-4}$ & $(1.4141 \pm 0.0089) \cdot 10^{-4}$ & $(1.228 \pm 0.052) \cdot 10^{6}$ & 0.040 \\
\hline
\end{tabular}

Table 9. $l$-type doubling constants calculated for the $0000^{0} 3^{1}$ vibrational state of $\mathrm{D}^{12} \mathrm{C}^{14} \mathrm{~N}^{16} \mathrm{O}$.

\begin{tabular}{cccr}
\hline$J$ & $\begin{array}{c}\text { Observed } \\
\text { frequencies } \\
\mathrm{MHz}\end{array}$ & $\begin{array}{c}\text { Calculated } \\
\text { frequencies } \\
\mathrm{MHz}\end{array}$ & $\begin{array}{c}\text { Obs.-calc. } \\
\mathrm{MHz}\end{array}$ \\
\hline 13 & 10646.49 & 10646.55 & -0.06 \\
14 & 12282.76 & 12282.76 & 0.00 \\
15 & 14035.38 & 14035.38 & 0.00 \\
16 & 15904.21 & 15904.19 & +0.02 \\
17 & 17889.16 & 17889.17 & -0.01 \\
18 & 19990.16 & 19990.14 & +0.02 \\
19 & 22207.04 & 22207.00 & +0.04 \\
20 & 24539.55 & 24539.59 & -0.04 \\
21 & 26987.66 & 26987.73 & -0.07 \\
22 & 29551.35 & 29551.33 & +0.02 \\
23 & 32230.14 & 32230.13 & +0.01 \\
24 & 35023.99 & 35023.98 & +0.01 \\
\hline
\end{tabular}

Table 10. Direct $l$-type doublet transitions measured for the $0000^{0} 3^{1}$ state of $\mathrm{D}^{12} \mathrm{C}^{14} \mathrm{~N}^{16} \mathrm{O}$. The calculated frequencies were obtained by using the constants given in Table 9, method II.

2) the value of the constant $\Delta, 1.228 \cdot 10^{6} \mathrm{MHz} \cong$ $41 \mathrm{~cm}^{-1}$, is surprisingly large.

As in the case of HCNO, these effects may best be explained through the vibrational dependence of $q$ together with anharmonic resonance interactions.

To summarize, the most important results of comparing the measurements of the microwave spectrum of HCNO and DCNO are the following:

1) The $r_{\mathrm{s}}$ structure may be determined to within an accuracy of $0.001 \AA$ or better, even though the $\mathrm{N}$-coordinate could not be obtained through substitution.
2) The rotation-vibration interaction in the two molecules shows significant differences

a) in the value of $q_{4}{ }^{(0)}$,

b) in the centrifugal distortion effects in the $l$-type doubling transition series for $v_{4}=1$,

while close parallels were observed

a) in the deviation of $\alpha_{0000^{\circ} 2^{\circ}}$ from the predicted value, and

b) in the change of $q_{5}{ }^{(0)}$ from $v_{5}=1$ to $v_{5}=3$.

The numerical correspondence of these last two points is shown in Table 11 to facilitate the comparison. The close quantitative relationship confirms the likelihood that the cause of these deviations is the same in both molecules.

\section{Acknowledgments}

This research was carried out in the Abteilung für Physikalische Chemie of the University of Ulm and we would like to thank Professor Dr. W. ZEIL for the opportunity of using the microwave spectrometer lent him by the Deutsche Forschungsgemeinschaft. The calculations were carried out at the Deutsches Rechenzentrum in Darmstadt, whom we would also like to thank for the use of library programs. The authors would like to thank Dr. BRENDA P. WINNEWISSER for her helpful comments on the manuscript.

\begin{tabular}{|c|c|c|c|c|c|c|}
\hline & \multicolumn{2}{|c|}{$\alpha_{0000} 0_{2} 0$} & \multirow{2}{*}{$\begin{array}{c}\text { Deviation } \\
\text { in } \\
\%\end{array}$} & \multicolumn{2}{|r|}{$q_{3 \times 5}^{(0)}$} & \multirow{2}{*}{$\begin{array}{l}\text { Deviation } \\
\quad \text { in } \%\end{array}$} \\
\hline & $\begin{array}{c}\text { measured } \\
\mathrm{MHz}\end{array}$ & $\begin{array}{l}\text { calculated } \\
\mathrm{MHz}\end{array}$ & & $\begin{array}{c}\text { measured } \\
\mathrm{MHz}\end{array}$ & $\begin{array}{l}\text { calculated } \\
\mathrm{MHz}\end{array}$ & \\
\hline HCNO & -46.69 & -60.34 & 23 & 27.0920 & 34.63 & 22 \\
\hline DCNO & -69.73 & -92.44 & 25 & 29.2748 & 38.09 & 23 \\
\hline
\end{tabular}

Table 11. Comparison between the anomalies in the constants $\alpha_{0000^{0} 2^{0}}$ and $q_{3 \times 5}^{(0)}$ for $\mathrm{H}^{12} \mathrm{C}^{14} \mathrm{~N}^{16} \mathrm{O}$ and $\mathrm{D}^{12} \mathrm{C}^{14} \mathrm{~N}^{16} \mathrm{O}$. 